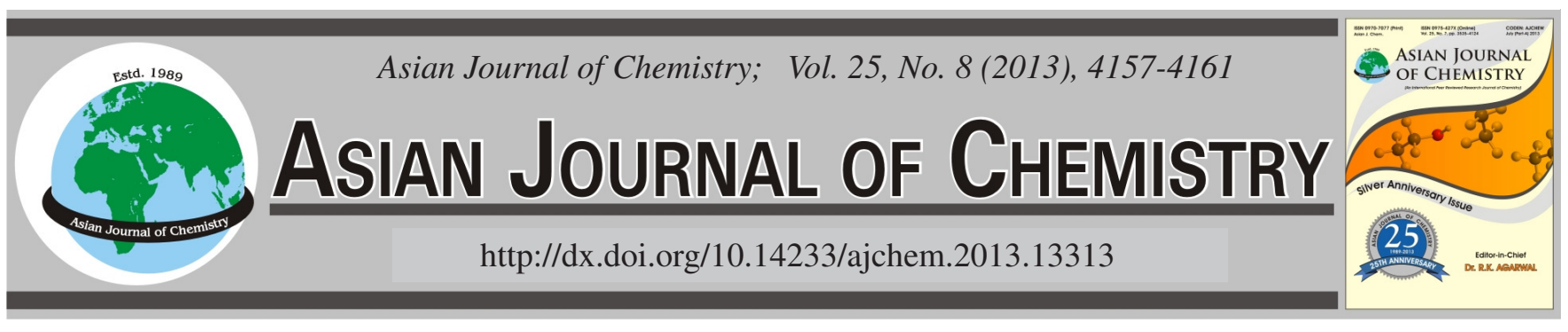

\title{
Surface-Modification Hyperbranched Polyaminoester Connected to Fused-Silica Capillary Microchips for Protein UV Analysis
}

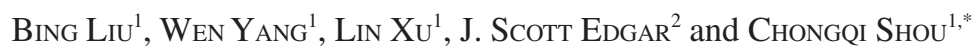

${ }^{1}$ School of Chemistry and Chemical Engineering, University of Jinan, Jinan 250022, P.R. China

${ }^{2}$ Department of Medicinal Chemistry, University of Washington, Box 357610, Seattle, WA 98195-7610, USA

*Corresponding author: Tel/Fax: +86 531 82767867; E-mail: scq211@163.com

(Received: 28 January 2012;

Accepted: 4 February 2013)

AJC-12917

\begin{abstract}
A "double-T" poly(dimethyl siloxane) microfluidic chips with $50 \mu \mathrm{m}$ separation channel and $200 \mu \mathrm{m}$ fabricated by the shooting technique. $10 \mathrm{~cm}$ fused-silica capillary was connected with the microfluidic chip through the tail end of the microchannel. With this method the dead volume which resulted from the connecting could be reduced effectively. Hyperbranched polyaminoesters with multiple hydroxy groups and perfect hydrophilic were synthesized by one-step technique. Then, chips were modified by hyperbranched polyaminoesters, which were treated in oxygen atmosphere in advance. The surface of poly(dimethyl siloxane) after modification was characterized using atomic force microscopy and scanning electron microscope.Through these methods the contact angles of poly(dimethyl siloxane) were lowered, that could inhibit the protein adsorption and electroosmotic flow of microchannel effectively. $2 \mathrm{mg} / \mathrm{mL} \mathrm{Adenosine} \mathrm{and}$ L-tryptophan were detected and separated by UV analysis. This study provides a new and rapid method of protein microfluidic chip modification.
\end{abstract}

Key Words: Microfluidic chip, Hyperbranched polyaminoester, Surface modification, UV Detection, Amino acid separation.

\section{INTRODUCTION}

Microfluidic devices for electrophoretic separation have developed rapidly in recent years ${ }^{1,2}$. Compared with conventional chemical analysis methods, microfluidic devices offer distinct advantages over traditional techniques including smaller device size, faster analysis speed, lower consumption analytes and disposability ${ }^{3,4}$. Due to a variety of surface properties microfluidic devices have been fabricated in glass, silica, poly(dimethyl siloxane) (PDMS) and poly(methmenthacrylate $)^{5-12}$ to name just a few. The use of polymer materials in microfluidic devices has increased rapidly in recent years due to ease of fabrication and low cost ${ }^{13,14}$. Among polymers PDMS is the most widely used for fabricating microfluidic devices. The attractive propertiess of PDMS include excellent chemical stability, durability, transparence, self-sealing capability, innocuity and biocompatibility. In addition, biocompatibility with living cells makes PDMS a good choice for biologic analysis leading to widespread use in biological applications.

However, PDMS has some disadvantages which limit its application in microfluidic systems. First, the surface of PDMS is highly hydrophobic, which causes undesired adsorbption of analyte and interferes with separations ${ }^{15}$. In addition, the hydrophobic nature of PDMS may cause air bubbles in the microchannel resulting in electrical shorting during separation. Secondly, PDMS is a porous material which can cause the distortion of the microchannels and shorten the life of microfluidic devices. Consequently, numerous methods have been developed to address the surface properties of PDMS.

Plasma treatment ${ }^{16,17}, \mathrm{UV} / \mathrm{O}_{3}$ treatment $^{18,19}$, coating microchannels with hydrophilic polymers ${ }^{20-22}$ and UV-mediated grafting ${ }^{23}$, have been utilized to treat the surface of PDMS and obtained promising results. However, there are still some disadvantages with the previously mentioned methods. For example, oxidation treatment can oxidize the silanols of the surface of PDMS to carboxylic acids causing the surface to become hydrophilic. This is not permanent and the hydrophobicity will gradually recover in a few hours ${ }^{23,24}$. Recently, grafting hydrophilic polymers onto the PDMS surface has become a popular method for surface modification. In this process, the polymers must have hydrophilic groups, low viscosity and a large degree of mobility. Two linear polymer poly(ethylene glycol) (PEG) ${ }^{25}$ and hydrophilic epoxy resin are commonly used in this method. Several factors, including molecular weight, viscosity, mobility, $\mathrm{pH}$ and the grafting density, affect the process of surface modification. Therefore, it is necessary to find a new type of hydrophilic material to replace the afore mentioned polymers, which not only changes 
the hydrophobicity of PDMS and reduces the adsorption of analytes but also offers improved functionality of the microfluidic devices when it is imparted.

Here, hyperbranched polymers with multiple peripheral functional groups ${ }^{26,27}$ could accord with the demands. Compared with linear polymers, hyperbranched polymers have lower viscosity resulting in even coated microchannels due to the relative ease of filling. Hyperbranched polymers have also a number of peripheral functional groups which is better to restrain electro-osmotic flows and reduce the adsorption of the analytes. We show that PDMS microfluidic chips coated with hyperbranched polyaminoesters (HPAEs) have excellent hydrophilicity, could increase the hydrophilicity of the PDMS surface and restrain electro-osmotic flows significantly. In order to perform protein UV analysis a length of fused-silica capillary was connected to the microchip.

\section{EXPERIMENTAL}

Sylgard 184 and condensate were purchased from Dow Corning. Diethanolamine, ethanol, methyl acrylate, 1,1,1trishydroxymethyl- propane and $p$-toluenesulfonic acid were obtained from China National Medicines Corporation Ltd and used without further purification. L-Tryptophan and adenosine were born from Beijing Biodee Ltd.

\section{Synthesis of hyperbranched polyaminoesters (HPAEs):} Hyperbranched polyaminoesters were synthesized (Fig. 1) from N,N-dihydroxy ethyl-3- amino methyl propionates, which were synthesized with diethanolamine and methyl acrylate (Fig. 1) and 1,1,1,-trimethylolpropanes which were used for cores. The detailed processes is shown in Fig. 1.<smiles>C=CC(=O)OC</smiles><smiles>CCC(C)(CO)CO</smiles>
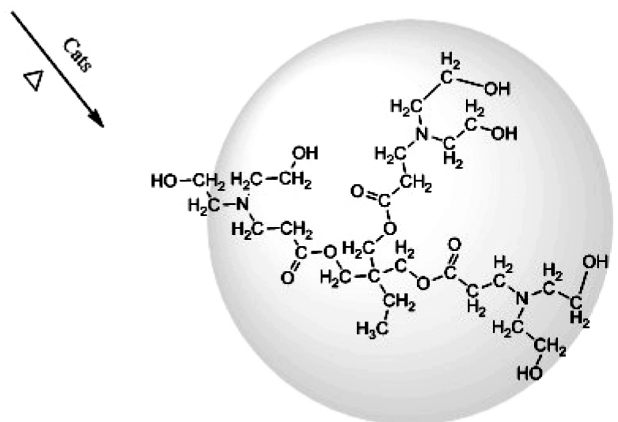

Fig. 1. Synthetic process of N,N-dihydroxyethyl-3-aminomethyl propionate. This process occurred at $35^{\circ} \mathrm{C}$ in methanol solution for $4 \mathrm{~h}$. Synthesis of HPAE-1. In this process, HPAEs with different molecular weights were synthesized in different mole ratios of reactants. The mole ratios of 1,1,1,-trimethyl-olpropanes and $\mathrm{N}, \mathrm{N}$ dihydroxyethyl-3-aminomethyl propionates, 1:9, 1:21 and 1:45, HPAE-2, HPAE-3 and HPAE-4 were synthesized. HPAEs have threedimensional netty structure, which looks like a ball. This kind of structure results in HPAEs with lower viscosity and the number of peripheral hydroxyls give HPAEs excellent hydrophilicity
Devices fabrication and joint preparation: The microchannel was designed with a double 'T'. To facilitate the coupling of capillary a low dead volume channel enabling the direct insertion of the capillary column was developed (Fig. 2). The procedure followed was reported previously ${ }^{28}$.

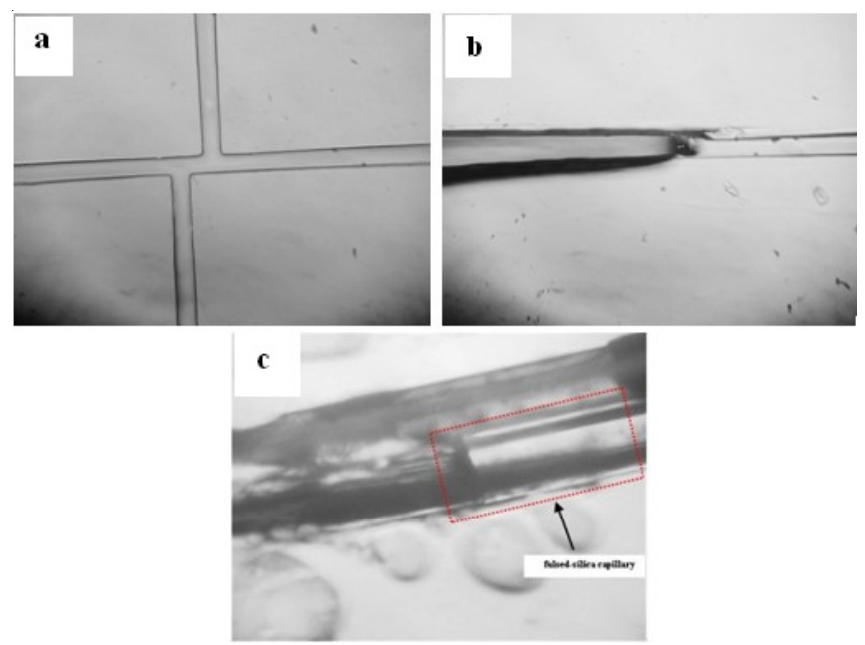

Fig. 2. CCD photographs of the microchannels. (a) A double "T" was microfabricated with a width of $50 \mu \mathrm{m}$. (b) A $200 \mu \mathrm{m}$ width microchannel was fabricated at the end of the channel and was used to connect with capillary column to reduce the dead volume. (c) The photograph of the chip connected with capillary column

Surface modification: According to Fig. 3, modification of PDMS based microfluidic channels starts from the solutionphase oxidation reaction of PDMS surfaces (1), which was carried out by continuously passing a mixture of $\mathrm{H}_{2} \mathrm{O}_{2}(30 \mathrm{wt}$ $\%)$ and $\mathrm{NaOH}(1 \mathrm{~mol} / \mathrm{L})$ through the microchannels for $1 \mathrm{~h}$. After purging the microchannels with deionized (DI) water and dry $\mathrm{N}_{2}$, the hydrophilic silanol-covered PDMS surfaces
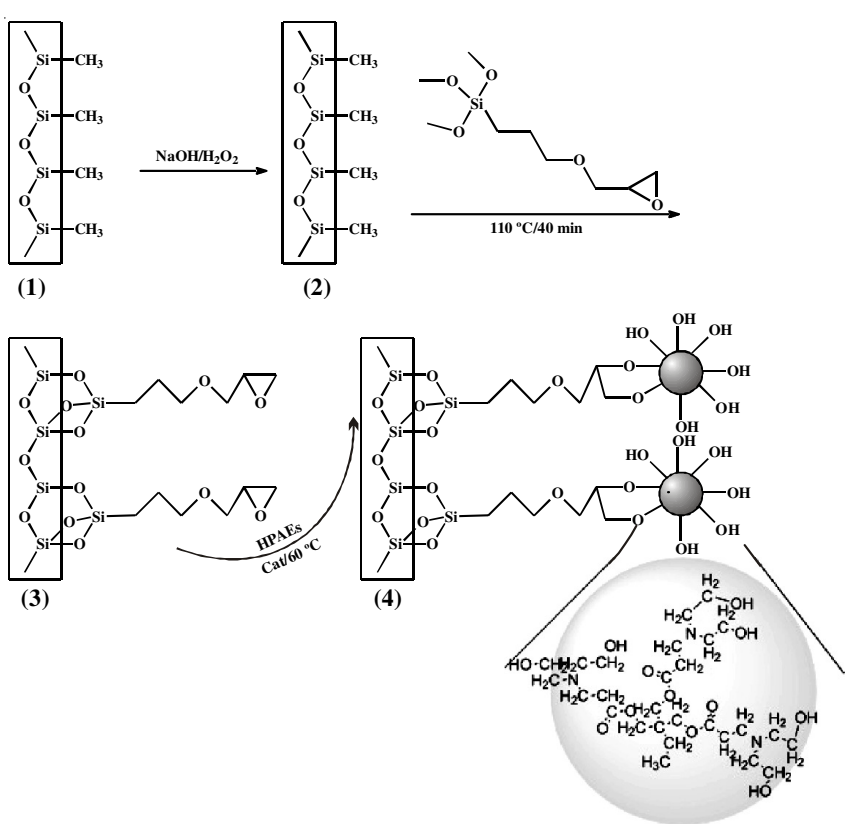

Fig. 3. Process of surface modification of PDMS. (1) The native-PDMS. (2) oxidated-PDMS. (3) Grafted with trimethoxy[3-(oxiran-2ylmethoxy)propyl]silane PDMS. (4) HPAEs grafted PDMS 
(2) were obtained. Sequentially, neat trimethoxy[3-(oxiran-2ylmethoxy)propyl]silane methanol solution $(10 \mathrm{wt} \%)$ was injected into the hydrophilic microchannels (2) to perform silanization reactions at room temperature for $40 \mathrm{~min}$ at 110 ${ }^{\circ} \mathrm{C}$. The unreacted silane coupler was flushed from the microchannels with deionized water to give the HPAEs-grafted microfluidic channels (4), which were dried by $\mathrm{N}_{2}$ flow and preserved in Petri dishes ${ }^{29,30}$.

Measurement of the contact angle: Contact angles were measured on flat PDMS films with varying surface coated HPAEs. A droplet of deionized water was placed on the air-side surface of a film at room temperature. After $30 \mathrm{~s}$ the contact angle was measured using a contact angle goniometer. The average of five measurements was taken for each droplet.

Measurement of the electro-osmotic flow (EOF): The current monitoring method was used to measure electroosmotic flow in the microfabricated channels. Measurements were performed as previously reported ${ }^{31}$. Four measurements were performed on each device. A single straight channel $3 \mathrm{~cm}$ in length was used for the measurements. The channel's width at the bottom, middle and top was 30,60 and $75 \mu \mathrm{m}$, respectively. The channel was $15 \mu \mathrm{m}$ deep in the center. To measure the stability of electro-osmotic flow after exposure to air, the channels were flushed with water, dried under a vacuum and then exposed to air at room temperature. At the times indicated, the channels were filled with aqueous buffer and $\mu_{\text {eo }}$ was measured. After the measurement, the channels were flushed with water, dried under a vacuum and again exposed to air at room temperature until the next electro-osmotic flow measurement.

Separation application: The separation buffers and sheath solution were prepared with aqueous $40 \mathrm{mM}$ phosphate buffer adjusted to different $\mathrm{pH}$ using $40 \mathrm{mM}$ sodium hydroxide. A $1 \mathrm{mg} / \mathrm{mL}$ adenosine and L-tryptophan solution was prepared. All aqueous solutions were filtered through a $0.45 \mu \mathrm{m}$ filter and underwent ultrasonic deaeration before used.

\section{RESULTS AND DISCUSSION}

Characterization of hyperbranched polyaminoesters (HPAEs): Fourier transform infrared spectra in the range of $4000-400 \mathrm{~cm}^{-1}$ were recorded on a FTIR TENSOR ${ }^{27}$. The FTIR spectra of G2, G3 and G4 are shown in Fig. 4. A broad absorption band at $3600-3100 \mathrm{~cm}^{-1}$ indicated the presence of hydroxyl groups. The characteristic peaks at $2960-2850 \mathrm{~cm}^{-1}$ were assigned to the methyl and methylene group. Another characteristic peak at the 1730 and $1618 \mathrm{~cm}^{-1}$ absorption bands were due to carbonyl stretching and $\mathrm{C}-\mathrm{N}$ stretching. Other FTIR absorption bands appear because of - $\mathrm{CH}$ - bending vibration (1470-1430 $\mathrm{cm}^{-1}$ ) and $-\mathrm{CH}_{3}$ bending vibration (1380$1355 \mathrm{~cm}^{-1}$ ). The FTIR spectra of G2, G3 and G4 were quite similar because their chemical structure is very similar.

Hydroxyl number means quantity of consumption of $\mathrm{KOH}$ for titrating $1 \mathrm{~g}$ HPAEs. and then get the hroxyl number with the quantity of consumption aetic anhydride that value can be gotten by the cost of anhydride for titration $\mathrm{KOH}$. Accurate to call for a certain number of samples and dissolved them in acetic anhydride/pyridine $(\mathrm{v} / \mathrm{v}=1: 5)$ blended solution. After that, increase the temperature to $110^{\circ} \mathrm{C}$ and kept the temperature

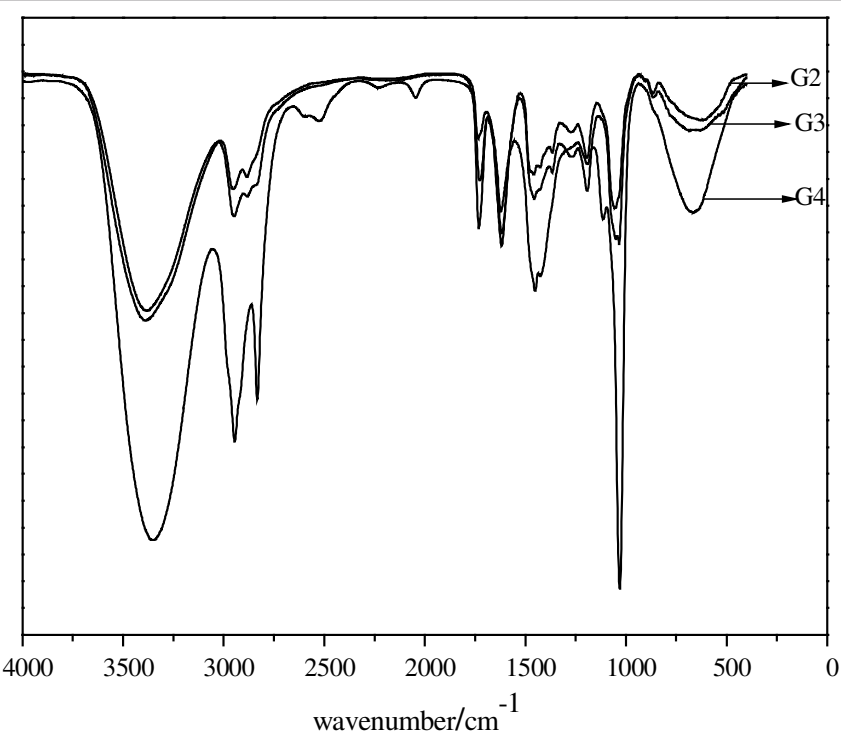

Fig. 4. IR spectra of HPAE-2, HPAE-3, HPAE-4

TABLE-1

HYDROXYL NUMBERS OF HPAES

\begin{tabular}{lccc}
\hline \multicolumn{1}{c}{ Hydroxyl numbers } & G2 & G3 & G4 \\
\hline Theoretical value $\left(\mathrm{mg} \mathrm{KOH} \mathrm{s}^{-1}\right)$ & 418.7 & 381.1 & 366.4 \\
Field data $\left(\mathrm{mg} \mathrm{KOH} \mathrm{s}^{-1}\right)$ & 410.2 & 372.5 & 356.4 \\
\hline
\end{tabular}

for $1.5 \mathrm{~h}$ in order to acetylation. Then, the cooling down solution was titrated with $0.5 \mathrm{~mol} / \mathrm{L} \mathrm{KOH}$ ethanol solution to determining the hdroxyl number of HPEAs. Hyperbranched polyaminoesters have higher hdroxyl numbers which could prove HPAEs have numbers of peripheral hydroxyls function groups.

Surface properties of modified poly(dimethyl siloxane): Water contact angles of the PDMS plates were measured and are shown in Table-2. They were $108.2 \pm 1.2^{\circ}, 72.4 \pm 3.2^{\circ}$, $70.1 \pm 2.2^{\circ}$ and $68.3 \pm 1.2^{\circ}$ for native-PDMS, HPAE-2-, HPAE-3and HPAE-4-coated PDMS surfaces, respectively. After oxidation treatment and coating the PDMS surface became relatively hydrophilic due to the formation of hydrophilic HPAEs layer. The water contact angles had a slight increase with the augmentation of the HPAE molecular weight, possibly due to the greater molecular weight the more hydrophilic groups presence.

TABLE-2

SURFACE PROPERTIES OF GRAFTED CHANNELS

\begin{tabular}{cccc}
$\begin{array}{c}\text { Surface } \\
\text { coating }\end{array}$ & Monomer & $\begin{array}{c}\text { Contact } \\
\text { angle }\left({ }^{\circ}\right)\end{array}$ & $\begin{array}{c}\mu_{\mathrm{eo}} \\
\left(\times 10^{-4} \mathrm{~cm}^{2} / \mathrm{Vs}\right)\end{array}$ \\
\hline Native-PDMS & - & $108.2 \pm 1.2$ & 3 \\
G2-PDMS & HPAE-2 & $72.4 \pm 3.2$ & $2.47 \pm 0.07$ \\
G3-PDMS & HPAE-3 & $70.1 \pm 2.2$ & $2.19 \pm 0.03$ \\
G4-PDMS & HPAE-4 & $68.3 \pm 1.2$ & $1.92 \pm 0.09$ \\
\hline
\end{tabular}

The surface morphology of modified PDMS was analyzed using atomic force microscopy (AFM). Fig. 5 shows the surface morphologies for PDMS modified by HPAE-G2, HPAE-G3 and HPAE-G4. The surface roughness values of PDMS modified by HPAE-G2, HPAE-G3 and HPAE-G4 were $1.105 \mathrm{~nm}$, $1.956 \mathrm{~nm}$ and $2.108 \mathrm{~nm}$, respectively. In contrast, the roughness of untreated PDMS surface is $0.35 \mathrm{~nm}^{31}$. The roughness values increased with the molecular weight. 

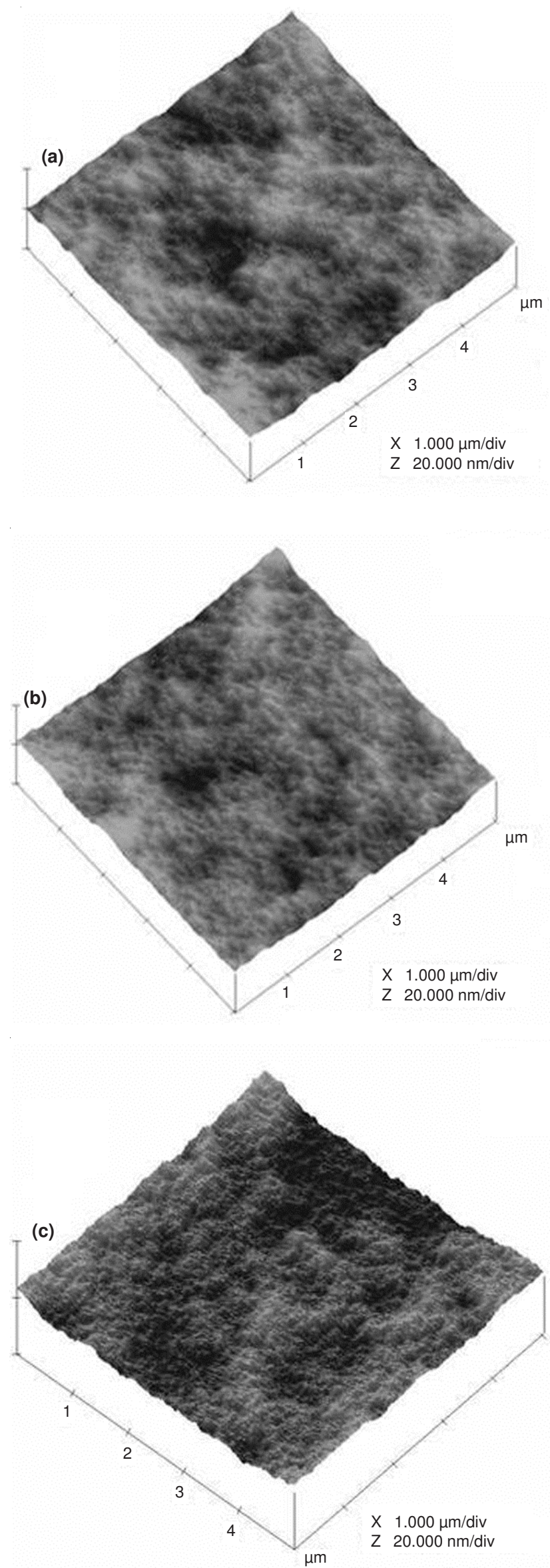

Fig. 5. AFM images of HPAE-G2 (a), HPAE-G3 (b) and HPAE-G4 modified PDMS (c)
In order to better visualize the grafted PDMS we took a series of scanning electron microscope (SEM) images which are shown in Fig. 6. There were compact and equally distributed flats of HPAEs on the surface of PDMS distinctly showing in Fig. 6 a, b, c. The microchannel walls were also coated by the HPAEs as shown in Fig. 6c and d.
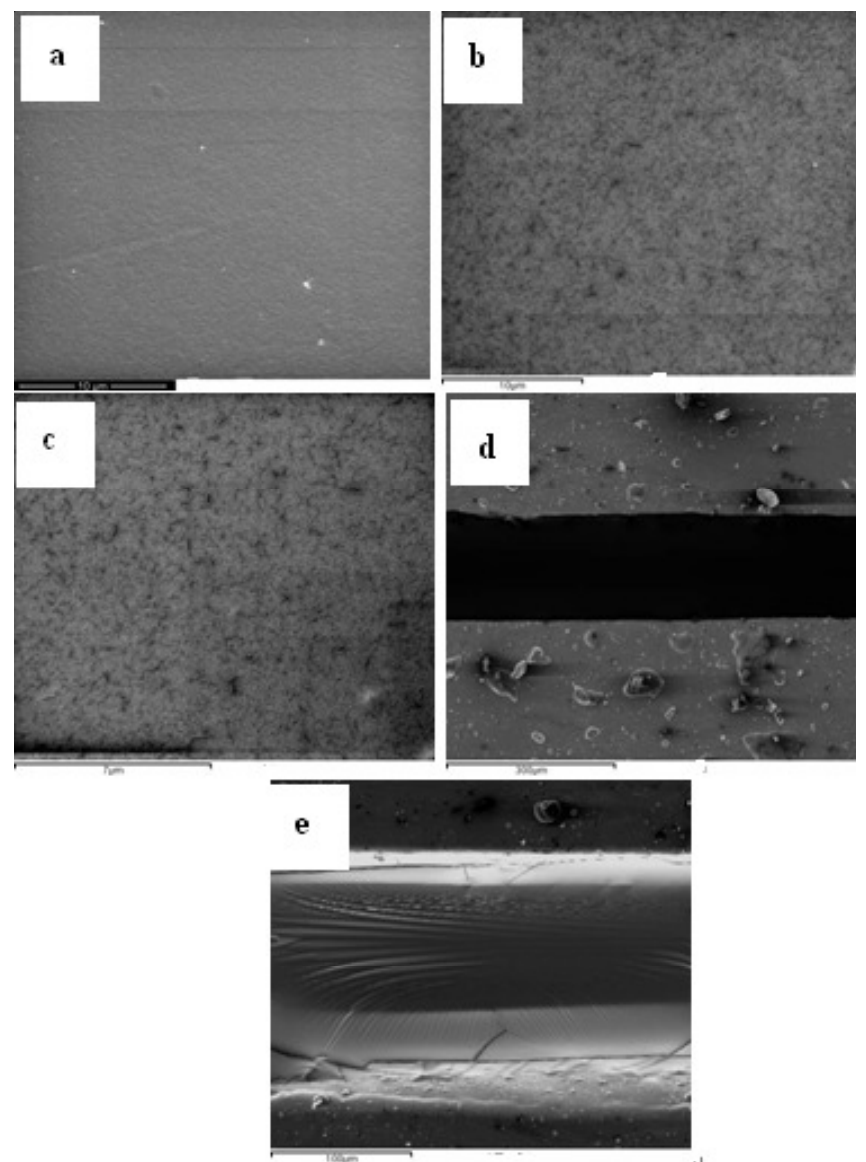

Fig 6 SEM micrographs of the surface of the PDMS and the microchannels untreated and grafted. (a) Uncoated PDMS film. (b), (c) Coated PDMS film. (d) Uncoated channel. (e) Coated channel

Measurement of electro-osmotic flow of modified poly(dimethyl siloxane) microchannels: To determine how the modified HPAEs altered eletro-osmotic fluid flow in microchannels, electro-osmotic flow was measured in channels modified with different HPAEs. In this study, electro-osmotic flow was measured over at $\mathrm{pH}=4.5$ in both modified and unmodified channels and the results are shown in Table-2. The $\mu_{\mathrm{eo}}$ in the native-PDMS was greater than in the grafted-PDMS and the $\mu_{\mathrm{eo}}$ reduced as the molecular weights increased. Obviously, the HPAEs could restrain the $\mu_{\mathrm{eo}}$ in the channels and with the molecular weights increasing the $\mu_{\mathrm{eo}}$ was smaller and smaller because of the numbers of peripheral functional groups of HPAE inceasing.

Protein UV separation: To determine the influence on separation, two proteins were separated with the chips using the afore mentioned method. A mixture solution of adenosine and L-tryptophan $(2 \mathrm{mg} / \mathrm{L})$ was made. Fig. 7a shows a typical electropherogram of protein mixture in phosphate buffer at pH 4.5 on uncoated and HPAEs-coated chips. The protein mixture could not be separated in the uncoated chip due to the 
adsorption on the inside surface of channel. At the same conditions, the protein mixture could be separated successfully in the three HPAEs-coated chips. The coated chips by HPAEs showed excellent separation performances, which are strongly related to their molecular structure. Hyperbranched polyaminoester contains large numbers of end-group hydroxyls, which could produce hydrogen bonding effectively with silanol hydrogens, therefore showing a stable coating was formed. This was because the average number of molecular periphery hydroxyl group was more, which absorbed to silanol groups existing in the channel inner wall increased. Thus, the degree of coverage was higher when the polymer was introduced in a channel.
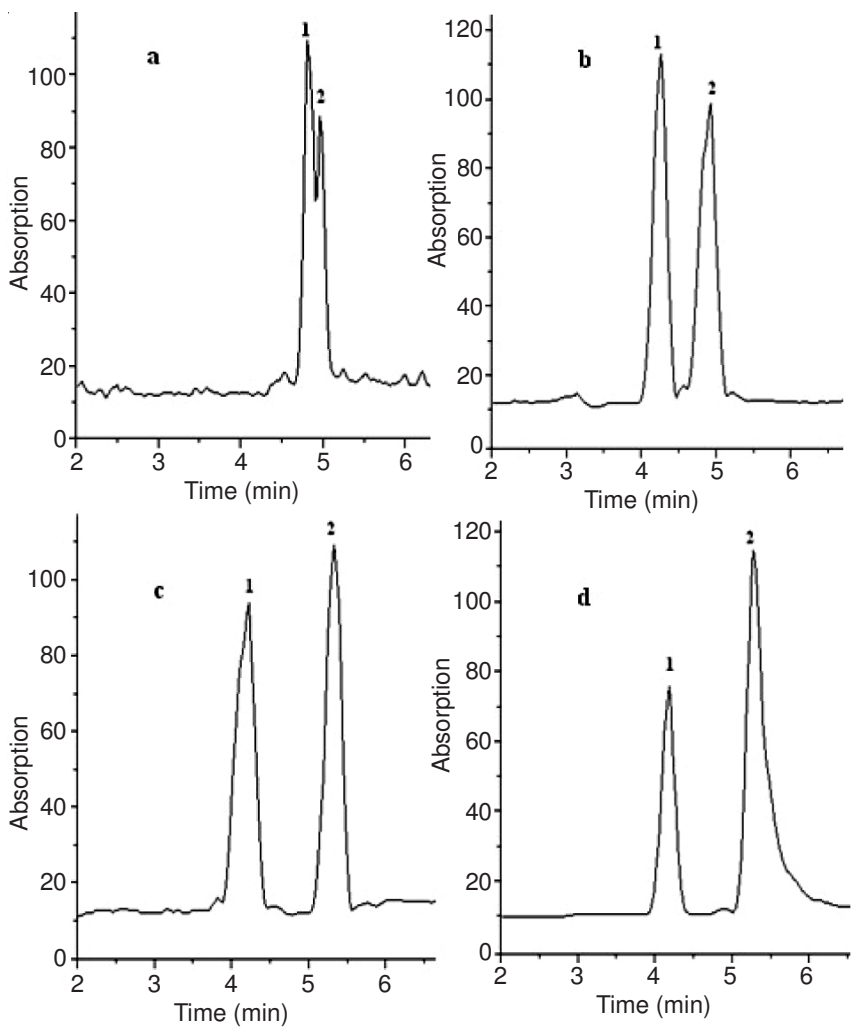

Fig. 7. Separation of adenosine and L-tryptophan in native-PDMS and grafted-PDMS channels. 1 is Adenosine and 2 is L-tryptophan, (a) Separation in a native-PDMS channel. (b) Separation in a grafted with HPAE-2. (c) Separation in a grafted with HPAE-3. (d) Separation in a grafted with HPAE-4

\section{Conclusion}

We have demonstrated the ability to tailor the surface properties of PDMS microfluidic devices for electrophoretic applications by grafting onto the surface. Three different monomers (HPAE-1, 2, 3) were used to produce three different classes of grafted surfaces. The preparation procedure of coated chips by HPAEs was fast and simple. The coated chips were able to effectively reduce electroosmotic flow and adsorption of proteins and successfully performed protein separation at the phosphate buffer $\mathrm{pH}=4.5$. The peripheral groups of HPAEs with high activity were easy to introduce to other functional groups, which provide a new approach to prepare for various chips with high special selectivity.

\section{ACKNOWLEDGEMENTS}

This project is supported by the Natural Science Foundation of Shandong Province (ZR2010BL003).

\section{REFERENCES}

1. D.R. Reyes, D. Iossifidis, P.A. Auroux and A. Manz, Anal. Chem., 74, 2623 (2002).

2. P.A. Auroux, D. Iossifidis, D.R. Reyes and A. Manz, Anal. Chem., 74, 2637 (2002)

3. S.C. Jakeway, A.J. de Mello and E.L. Russell, Anal. Chem., 366, 525 (2000).

4. T. Chovan and A. Guttman, Trends Biotechnol., 20, 116 (2002).

5. S.C. Jacobson, R. Hergenroder, L.B. Koutny and J. M. Ramsey, Anal. Chem., 66, 1114 (1994)

6. S.C. Jacobson, A.W. Moore and J.M. Ramsey, Anal. Chem., 67, 2059 (1995)

7. B.J. Kirby, A.R. Wheeler, R.N. Zare, J.A. Fruetel and T.J. Shepodd, Lab. Chip, 3, 5 (2003).

8. B. Huang, H.K. Wu and S. Kim, Lab Chip, 6, 369 (2006)

9. M.B. Wabuyele, S.M. Ford, W. Stryjewski, J. Barrow and S.A. Soper, Electrophoresis, 22, 3939 (2001).

10. H. Bi, S. Meng, Y. Li, K. Guo, Y. Chen, J. Kong, P. Yang, W. Zhong and B. Liu, Lab Chip, 6, 769 (2006).

11. J.K. Liu, T. Pan, A.T. Wooley and M.L. Lee, Anal. Chem., 76, 6948 (2004).

12. S.W. Hu, X.Q. Ren, M. Bachman, C.E. Sims, G.P. Li and N. Allbritton, Electrophoresis, 24, 3679 (2003).

13. J.C. McDonald, D.C.D. Anderson Jr, D.T. Chiu, H. Wu, O.J. Schueller and G.M. Whitesides, Electrophoresis, 21, 27 (2000).

14. S.W. Hu, X.Q. Ren, M. Bachman, C.E. Sims, G.P. Li and N. Allbritton, Langmuir, 20, 5569 (2004).

15. K. Miyaki, J. Chromatogr. A, 1166, 201 (2007).

16. S.R. Gaboury and M.W. Urban, Polymer, 33, 5085 (1992).

17. K. Efimenko, W.E. Wallace and J. Genzer, J. Colloid Interf. Sci., 254, 306 (2002).

18. Y. Berdichevsky, J. Khandurina and A. Guttman, Sens. Actuators B, 97, 402 (2004).

19. A. Olah, H. Hillborg and G. Vancso, J. Appl. Surf. Sci., 239, 410 (2005).

20. M. Drew, Surfactant Science and Technology, Wiley Services, Published Online (2005).

21. J. Seo and L.P. Lee, Sens. Actuators B, 119, 192 (2006).

22. A.J. Wang, J.J. Xu and H.Y. Chen, Anal. Chim. Acta, 569, 188 (2006).

23. S.W. Hu, X.Q. Ren, M. Bachman, C.E. Sims, G.P. Li and N. Allbritton, Anal. Chem., 74, 4117 (2002).

24. Y.H. Kim and O.W. Webster, Polym. Prepr., 29, 310 (1988).

25. S. Lee and J. Voros, Langmuir, 21, 1957 (2005).

26. Y.H. Kim and O.W. Webster, J. Am. Chem. Soc., 112, 4592 (1990).

27. T.H. Mourey, S.R. Tturner and J.M.J. Frecthet, Macromolecules, 25, 2401 (1992).

28. C.H. Chiou and G.B. Lee, J. Micromech. Microeng., 14, 1484 (2004).

29. M.Y. Ye, Q. Fang and X.F. Yin, Chin. J. Anal. Chem., 32, 1585 (2004).

30. G.D. Sui, J.Y. Wang and C.-C. Lee, Anal. Chim., 78, 5543 (2006).

31. X.Q. Ren, M. Bachman and C. Sims, J. Chromatogr. B, 762, 117 (2001). 